\title{
EI derecho a la vida privada de los funcionarios públicos frente al derecho de acceso a la información pública. Un estudio a la luz de la jurisprudencia del Consejo para la Transparencia en Chile The right to privacy of public officials versus the right of access to public information. A study in light of the jurisprudence of the Council for Transparency in Chile
}

Jorge Luis Astudillo Muñoz

Universidad Andrés Bello, Chile jastudillo@unab.cl

Recibido 24/01/2020

Aceptado 12/05/2020

Resumen: El presente trabajo presenta un breve análisis jurisprudencial de la doctrina sustentada por el Consejo para la Transparencia chileno respecto al derecho a la vida privada de los funcionarios de la Administración del Estado frente a los requerimientos formulados en ejercicio del derecho de acceso a la información. Dando por supuesto que los funcionarios públicos son titulares de derechos fundamentales, este artículo da cuenta, a través del estudio de casos particulares, de cómo el Consejo para la Transparencia ha entendido y sostenido que las personas que integran los órganos del Estado deben tolerar una reducción a su ámbito de privacidad debido a la naturaleza de las funciones que cumplen y el interés general que subyace en ellas. 
Jorge Luis Astudillo Muñoz

Palabras Clave: Derecho de Acceso a la información pública; privacidad; Consejo para la Transparencia, Chile.

\begin{abstract}
This work presents a brief jurisprudential analysis of the doctrine supported by the Chilean Council for Transparency regarding the right to private life of State Administration officials against the requirements formulated in exercise of the right of access to information. Assuming that public officials are holders of fundamental rights, this article reports, through the study of particular cases, how the Council for Transparency has understood and maintained that the people who make up the State organs must tolerate a reduction in their scope of privacy due to the nature of the functions they fulfill and the general interest that underlies them.
\end{abstract}

Keywords: Right of Access to public information; Privacy; Council for Transparency, Chile.

Sumario: I. Introducción. II. El derecho a la vida privada. III. El derecho a la vida privada de los funcionarios públicos frente a los requerimientos de acceso a la información pública. IV. Conclusiones. Bibliografía.

\title{
I. Introducción
}

La transparencia es uno de los principios rectores en los cuales se debe sustentar todo sistema democrático. Su consagración constitucional o legal es cada vez más aceptada como un mecanismo idóneo para lograr el fortalecimiento de la democracia y constituirse como una útil herramienta para el combate a la corrupción.

A pesar de todas sus debilidades y "promesas incumplidas" (Bobbio, 1986, p. 17-26), la democracia es la forma de gobierno más compatible con la dignidad humana. En este orden de cosas, siempre habrá buenas razones para preferirla, especialmente para todos aquellos que creemos en los derechos fundamentales y en su protección. En la medida que en democracia se minimiza la heteronomía en la creación de las reglas sociales fundamentales, en este tipo de gobierno se 
tiende a respetar más la libertad y la igualdad como valores cardinales del orden social.

La corrupción es un fenómeno que pone seriamente en riesgo la democracia. Son muchas las voces autorizadas que así lo entienden, por ejemplo, la Convención de Naciones Unidas contra la Corrupción lo afirma al señalar que la corrupción se trata de "una plaga insidiosa, (que) socava la democracia y el Estado de derecho, es la base de violaciones a los derechos humanos, distorsiona los mercados, permite el florecimiento de la delincuencia organizada, y en buenas cuentas, menoscaba la calidad de vida de las personas" (ONU, 2003). ${ }^{1}$

Considerando el peligro que la corrupción encierra, se deben prever mecanismos o herramientas que permitan enfrentarla y procurar reducirla al máximo. La transparencia y el acceso a la información pública son mecanismos útiles para esta tarea. En efecto, la transparencia se asocia a la idea de visibilidad, y en la medida que los actos de quienes ejercen poder o bien de aquellos que manejan recursos públicos sean visibles, se producirán a lo menos dos efectos: por un lado, se crea un incentivo en orden a evitar actos corruptos y, por otro, opera de manera más eficiente el control (jurídico-político, periodístico o ciudadano), y con ello los actos corruptos podrán ser detectados con mayor facilidad y se harán efectivas las responsabilidades asociadas al Estado de derecho. En otras palabras, la transparencia es un efectivo remedio contra el secretismo, escenario propicio para el desarrollo de la corrupción.

Una de las principales consecuencias que emanan del principio de transparencia en el ejercicio de la función pública es el reconocimiento del derecho de acceso a la información que se encuentra en poder de los órganos del Estado. El derecho de acceso a la información pública lo concebimos como un derecho de naturaleza iusfundamental que faculta a las personas para exigir la entrega de la información que obra en poder de los órganos del Estado y que según cada ordenamiento jurídico no se encuentra sometida a la reserva o secreto.

\footnotetext{
${ }^{1}$ Sobre corrupción y especialmente sobre corrupción política se recomienda: Bustos Gisbert, R. (2010). "Corrupción política: un análisis desde la teoría y la realidad constitucional". Teoría y realidad constitucional, 25, pp. 69-109; BUSTOS GISBERT, R. (2007).”Corrupción de los gobernantes, responsabilidad política y control parlamentario". Teoría y realidad constitucional,19, pp.135-161; Villoria Mendieta, M. (2006). La corrupción política. Madrid: Síntesis; Villoria Mendieta, M. (2000), "La corrupción política". Jueces por la democracia, 37, pp. 26-34; Laporta San Miguel, F. \& Álvarez Medina, S. (coord.) (1997). Madrid: Alianza.
} 
La Ley $\mathrm{N}^{\mathrm{o}} 20.285$, sobre acceso a la información pública (Chile), ${ }^{2}$ en su artículo $3^{\circ}$ dispone que "la función pública se ejerce con transparencia, de modo que permita y promueva el conocimiento de los procedimientos, contenidos y decisiones que se adopten en el ejercicio de ella". Por su parte, el artículo $4^{\circ}$ del mismo cuerpo legal prescribe que "las autoridades, cualquiera sea su denominación con que las designe la Constitución y las leyes, y los funcionarios de la Administración del Estado, deberán dar estricto cumplimiento al principio de transparencia de la función pública".

Estas disposiciones se complementan con el artículo $5^{\circ}$ de la misma Ley $\mathrm{N}^{\mathrm{o}}$ 20.285 que prescribe que "en virtud del principio de transparencia de la función pública, los actos y resoluciones de los órganos de la Administración del Estado, sus fundamentos, los documentos que les sirvan de sustento o complemento directo y esencial, y los procedimientos que se utilicen para su dictación, son públicos, salvo las excepciones que establece esta ley y las previstas en otras leyes de quórum calificado". El inciso segundo de este mismo artículo $5^{\circ}$ señala que "es pública la información elaborada con presupuesto público y toda otra información que obre en poder de los órganos de la Administración, cualquiera sea su formato, soporte, fecha de creación, origen, clasificación o procesamiento, a menos que esté sujeta a las excepciones señaladas".

En estricta concordancia con las disposiciones citadas, el artículo $10^{\circ}$ de la Ley No 20.285 expresa que "toda persona tiene derecho a solicitar y recibir información que obre en poder de cualquier órgano de la Administración del Estado, en la forma y condiciones que establece esta ley". Además, se indica que "el acceso a la información comprende el derecho de acceder a las informaciones contenidas en actos, resoluciones, actas, expedientes, contratos y acuerdos, así como a toda la información elaborada con presupuesto público, cualquiera sea el formato o soporte en que se contenga, salvo las excepciones legales".

Una de las causales que autoriza a denegar la información requerida en ejercicio del derecho de acceso a la información pública, es el respeto a los derechos de las personas. Así lo dispone expresamente la Constitución chilena en su artículo 8 y la Ley $\mathrm{N}^{\mathrm{o}} 20.285$ en su artículo $21 \mathrm{~N}^{\circ} 2$.

\footnotetext{
${ }^{2}$ Para más detalles sobre la normativa chilena: Vivanco Martínez, A. ((2008). "Transparencia de la función pública y acceso a la información de la Administración del Estado". Revista Chilena de Derecho, 35, 2, pp. 371-391.
} 
Dentro del contexto social, político y jurídico precedentemente expuesto, el presente estudio tiene por finalidad abordar cómo se concilia el derecho de acceso a la información pública con el derecho a la vida privada de los funcionarios públicos por parte de la jurisprudencia del Consejo para la Transparencia (también CPT) en el modelo chileno.

De este modo, comenzaremos por precisar brevemente cuál es el contenido del derecho a la vida privada, advirtiendo que el desarrollo de esta parte del presente trabajo será particularmente breve, a fin de evitar el abuso en su extensión y porque el tema central no es abordar el derecho a la vida privada a cabalidad, sino proponer un estudio a partir de decisiones adoptadas por el CPT en donde ha ido precisando las relaciones entre el derecho fundamental a la vida privada y el derecho de acceso a la información pública respecto de los funcionarios públicos de la Administración del Estado.

Posteriormente se presenta el análisis de algunas decisiones relevantes del CPT a través de las cuáles ha ido abordando la tensión entre ambos derechos, resaltando que si bien la titularidad en el ejercicio de la función pública no trae consigo que las personas dejen de ser titulares del derecho a la vida privada, los estándares y criterios para su protección son diversos a los que proceden respecto de personas que no son parte del aparato estatal. Advertimos que este breve estudio solo se centra en la producción jurisprudencial del CPT y no expone la posición que la justicia ordinaria ha asumido conociendo de los reclamos de legalidad que se han deducido en contra de las resoluciones de dicho órgano. Lo anterior se debe a que la finalidad del presente trabajo es mostrar exclusivamente la posición que el CPT ha sustentado respecto de la vida privada de los funcionarios de la Administración del Estado frente a requerimientos de información pública efectuados por la ciudadanía. 
Jorge Luis Astudillo Muñoz

\section{EI derecho a la vida privada}

Si bien algunos autores distinguen entre los conceptos de vida privada o privacidad e intimidad, ${ }^{3}$ para los efectos de la presente exposición no nos haremos cargo de estas distinciones y solo usaremos la expresión vida privada. De todas formas, valga recordar que "el surgimiento del sentimiento de la intimidad aparece en fechas recientes, en la sociedad posindustrial, como un nuevo giro, un nuevo repliegue del individuo sobre sí mismo abandonado la privacidad intersubjetiva para recluirse en su interior, en un nuevo espacio intrasubjetivo. Ya no es reclusión en la vida privada, en la vida amurallada con la familia y los amigos, sino en la vida interior, en lo más profundo de nuestro ser, en la intraconciencia, donde se examinan los afectos, los pensamientos, la opiniones personales. Y los recuerdos, las fantasías, donde soñamos, amamos, y odiamos, y envidiamos" (Martínez de Pisón, 1997, p. 721). En la misma línea, "cuando se alude al derecho a la intimidad sus implicaciones son hacia los sentimientos, pensamientos, pudor, sexualidad, secreto y todo aquello que forma parte de lo más interior y reservado del individuo" (Cobos, 2013, p. 79).

El derecho a la vida privada se encuentra estrechamente vinculado a la dignidad y a la libertad del ser humano. Si bien es cierto vivimos insertos en una vida social de la cual no nos podemos sustraer, el reconocimiento y protección de una esfera de privacidad resulta esencial para el pleno desarrollo del individuo.

El Tribunal Constitucional (Chile) ha declarado que "el respeto y protección de la dignidad y de los derechos a la privacidad de la vida y de las comunicaciones, son base esencial del desarrollo de la libre personalidad de cada sujeto, así como de su manifestación en la comunidad a través de los grupos intermedios autónomos con que se estructura la sociedad" (Rol 389-03, considerando 21). En definitiva, el reconocimiento y protección de un ámbito de privacidad es necesario "para mantener una calidad mínima de la vida humana" (Tribunal Constitucional español, 231/1988, fundamento 3).

\footnotetext{
${ }^{3}$ Consultar: Sanz Salguero, F.J. (2018). "Delimitación de las esferas de la vida privada, privacidad e intimidad, frente al ámbito de lo público". Transparencia y Sociedad, 6, pp. 127-149; Toscano, M. (2017). "Sobre el concepto de privacidad: la relación entre privacidad e intimidad”. Revista de Filosofía Moral y Política, pp. 533-552.
} 
Se trata de un derecho que tiene expreso reconocimiento en el derecho internacional de los derechos humanos y en los distintos ordenamientos internos. Así se recoge en el artículo 12 de la Declaración Universal de Derechos Humanos de 1948, en el artículo 11 de la Convención Americana de Derechos Humanos de 1969 y en el artículo 8 del Convenio Europeo de Derechos Humanos de 1950.

La doctrina especializada entiende el derecho a la vida privada como la facultad de sustraer del conocimiento de terceros ciertas circunstancias de nuestra vida y respecto de las cuales no deseamos que estos tengan conocimiento. Así, se ha definido el derecho a la vida privada como "el derecho de toda persona a mantener fuera del conocimiento de terceros aquellos aspectos de su vida corporal o anímica que le provocan recato o pudor, aunque no afecten su honor, imagen o integridad física o mental, toda vez que le resultan íntimos, no obstante, la falsedad o veracidad objetiva de sus contenidos" (Suárez, 2000, p. 110). Díez-Picazo lo entiende como "la facultad de excluir del conocimiento ajeno cualesquiera hechos comprendidos dentro de un ámbito propio y reservado" (Díez-Picazo, 2005, p. 288).

A pesar de que es posible detectar un gran número de definiciones doctrinarias, la vida privada no puede ser objeto de definiciones establecidas en forma muy restringida y de antemano por el derecho, ya que con ello se corre el riesgo de reducir en forma intolerable su ámbito de protección. El Tribunal Europeo de Derechos Humanos (TEDH) ha entendido que el concepto de vida privada no puede ser objeto de definiciones exhaustivas. ${ }^{4}$ Así, en el Caso Peck contra Reino Unido, ${ }^{5}$ el Tribunal de Estrasburgo sostuvo que "elementos como la identificación de género, el nombre, la orientación sexual y la vida sexual son elementos importantes de la esfera personal protegidos por el artículo 8" (Peck v. Reino Unido, 2003, párrafo 57). Además, el TEDH ha resuelto que en este artículo 8 también se "protege el derecho a la identidad y el desarrollo personal, y el derecho a establecer y desarrollar relaciones con otros seres humanos y el mundo

\footnotetext{
${ }^{4}$ De igual modo se ha pronunciado la Corte Interamericana de Derechos Humanos. Ver: Caso Fernández Ortega contra México, 30 de agosto de 2010, párrafo 129; Caso Rosendo Cantú y otra contra México, 31 de agosto de 2010, párrafo 119.

${ }^{5}$ En el mismo sentido: Caso Axel Springer AG contra Alemania, 39954/08, 7 de febrero de 2012, párrafo 83; Caso S. And Marper contra Reino Unido, 30562/04 - 30566/04, 4 de diciembre de 2008, párrafo 66; etc.
} 
exterior y puede incluir actividades de naturaleza profesional o comercial. Por lo tanto, existe una zona de interacción de una persona con otras personas, incluso en un contexto público, que puede caer dentro del alcance de la vida privada".

En la misma línea, casi diez años antes que Peck, en el marco del Caso Niemietz con Alemania, el TEDH señalaba que sería demasiado restrictivo limitar la noción de vida privada a un "círculo interno" en el que el individuo pueda vivir su propia vida personal según lo elija y excluir de él por completo el mundo exterior que no está incluido dentro de ese círculo. En consecuencia, el ámbito de protección a la vida privada también debe comprender "el derecho a establecer y desarrollar relaciones con otros seres humanos" (Caso Niemietz con Alemania, 1992, párrafo 29).

Este último fallo es particularmente interesante e importante, pues el TEDH reconoce expresamente "que no hay ninguna razón de principio por la cual esta comprensión de la noción de vida privada deba considerarse para excluir actividades de naturaleza profesional o comercial, ya que es, después de todo, en el curso de sus vidas laborales en las que la mayoría de las personas tienen una oportunidad significativa, sino la mejor, de desarrollar relaciones con el mundo exterior".

La Corte Interamericana de Derechos Humanos (CIDH) ha sostenido por su parte que "la protección a la vida privada abarca una serie de factores relacionados con la dignidad del individuo, incluyendo por ejemplo la capacidad para desarrollar la propia personalidad y aspiraciones, determinar su propia identidad y definir sus propias relaciones personales. El concepto de vida privada engloba aspectos de la identidad física y social, incluyendo el derecho a la autonomía personal, desarrollo personal y el derecho a establecer y desarrollar relaciones con otros seres humanos y con el mundo exterior. La efectividad del ejercicio del derecho a la vida privada es decisiva para la posibilidad de ejercer la autonomía personal sobre el futuro curso de eventos relevantes para la calidad de vida de la persona. La vida privada incluye la forma en que el individuo se ve a sí mismo y cómo decide proyectarse hacia los demás, y es una condición indispensable para el libre desarrollo de la personalidad" (Caso Artavia Murillo y otros v. Costa Rica, 2012, párrafo 143). 
Como se puede apreciar de esta breve reseña jurisprudencial, "existe cierto consenso entre la Corte Interamericana de Derechos Humanos y el Tribunal Europeo respecto del amplísimo alcance del derecho a la vida privada, fundamentalmente en el sentido de que el derecho a vida privada comprende múltiples aspectos de la identidad de las personas y de cómo deciden relacionarse con otros seres humanos" (Maqueo, 2017, p. 88).

En este orden de cosas es innegable que las personas que ejercen funciones al interior de la estructura estatal gozan de un ámbito de protección a su vida privada e intimidad que debe ser reconocida y protegida por el derecho. El ejercer un cargo u oficio público no implica renunciar a la vida privada. Sin embargo, es necesario preguntarse si estas personas, que sin duda son titulares del derecho a la vida privada, deben tolerar un mayor grado de intromisión a la misma en razón a su calidad de funcionarios públicos.

En las páginas que siguen, responderemos esta pregunta a la luz de la jurisprudencia emanada del CPT en Chile y que se ha ido configurando en aplicación del derecho de acceso a la información pública en relación con las excepciones de reserva o secreto que contempla la Ley $\mathrm{N}^{\circ} 20.285$ sobre acceso a la información pública.

\section{EI derecho a la vida privada de los funcionarios públicos frente a los requerimientos de acceso a la información pública}

La transparencia y la publicidad son principios esenciales que inspiran el ejercicio de la función pública, por lo tanto, la publicidad de los actos de los órganos del Estado constituye la regla general y la reserva o secreto la excepción. Estas excepciones deben ser recogidas expresamente y las normas que las contienen no pueden ser interpretadas y aplicadas analógicamente. Además, ellas deben estar reconocidas solo en la Constitución o la ley y nunca en el reglamento. ${ }^{6}$

\footnotetext{
${ }^{6} \mathrm{El} \mathrm{CPT} \mathrm{ha} \mathrm{sostenido} \mathrm{reiteradamente,} \mathrm{en} \mathrm{una} \mathrm{doctrina} \mathrm{que} \mathrm{consideramos} \mathrm{correcta,} \mathrm{que} \mathrm{no} \mathrm{basta} \mathrm{con} \mathrm{que} \mathrm{el} \mathrm{órgano}$ estatal respectivo niegue la entrega de la información en base a una determinada causal de reserva o secreto;
} 
Las causales de reserva o secreto, en el sistema legal chileno, se encuentran reconocidas en el artículo $21^{\circ}$ de la Ley $\mathrm{N}^{\circ}$ 20.285. Una de las razones por las cuales un órgano de la Administración del Estado puede negarse válidamente a entregar información solicitada se configura "cuando su publicidad, comunicación o conocimiento afecte los derechos de las personas, particularmente tratándose de su seguridad, su salud, la esfera de su vida privada o los derechos de carácter comercial o económico".

En relación con esta causal, en las páginas que siguen, expondremos de qué manera el $\mathrm{CPT}^{7}$ en el sistema chileno ha ido configurando el ámbito de privacidad de los funcionarios públicos en aquellos casos en que se ha solicitado entrega de información que la pudiera comprometer.

El CPT "ha tenido que recurrir básicamente al empleo combinado de dos instrumentos para justificar la incursión, a nombre del ejercicio del derecho de acceso, en la esfera de la vida privada de los funcionarios públicos", afirma Covarrubias (2015, p. 227). El primero de estos instrumentos consiste en la tesis que sostiene que "los funcionarios públicos, poseen una esfera de vida privada más delimitada en virtud precisamente de la función que ejercen" (Covarrubias, 2015 , p. 227). El segundo, y estrictamente relacionado con el primero, ha sido el empleo del llamado "test del interés público", ${ }^{8}$ que básicamente consiste en realizar una ponderación entre el beneficio de liberar la información pública solicitada frente al perjuicio que su divulgación puede significar para los derechos de las personas. ${ }^{9}$

también tiene que estar en condiciones de fundamentar su decisión y acreditar que dicha causal efectivamente se configura. Así, "la afectación debe ser presente o probable, y con la suficiente especificidad que permita justificar la reserva, de modo que no cabe presumirla, sino que debe ser acreditada por el órgano administrativo requerido, de modo que los daños que la publicidad provocaría sean superiores al perjuicio que el secreto causaría al libre acceso de la información y al principio de publicidad" (СРT C1180-18).

${ }^{7}$ Según la Ley $N^{\circ} 20.285$ una corporación autónoma de derecho público, con personalidad jurídica y patrimonio propio, denominado Consejo para la Transparencia será la encargada de "promover la transparencia de la función pública, fiscalizar el cumplimiento de las normas sobre transparencia y publicidad de la información de los órganos de la Administración del Estado, y garantizar el derecho de acceso a la información".

${ }^{8}$ Consultar: Covarubias Cuevas, I. (2012). "Las falencias del test de interés público como instrumento de ponderación entre el acceso a la información pública y privada". Revista de Derecho (Valparaíso), 38, pp. 499-541.

${ }^{9}$ Sobre el concepto de interés público en relación con el derecho de acceso se recomienda: Droguett González, C. (2019) El interés público de la información en el ejercicio del derecho de acceso a la información pública. 
Efectivamente, desde sus primeros meses de funcionamiento, el CPT ha entendido que la esfera de vida privada de los funcionarios públicos es menor que la del resto de las personas que no se desempeñan dentro del aparato administrativo del Estado. Dado lo anterior, "la supuesta afectación de la honra de los funcionarios sancionados no puede ser fundamento suficiente para reconocer que la publicidad de tal expediente sumarial ni del informe en derecho respectivo sean considerados como secretos, toda vez que las personas involucradas, en cuanto funcionarios públicos, poseen una esfera de vida privada más delimitada en virtud precisamente de la función que ejercen, prevaleciendo en tal caso el interés público en conocer si existieron irregularidades en un órgano de la Administración del Estado, si dicho órgano tomó las medidas pertinentes para investigar y sancionar, en su caso, a los responsables y reparar los daños que dichas irregularidades pudieren haber causado" (CPT A47-09).

Entendemos que esta solución es correcta, ya que el ejercicio de la función pública implica un mayor grado de compromiso por parte de las personas que han decidido desempeñarse en ella, lo que es totalmente coherente con el principio de servicialidad del Estado y el principio democrático, por lo que los estándares de exigencia hacia ellos son mayores y las restricciones que deben tolerar al ejercicio de sus derechos no son las mismas que el resto de los ciudadanos. Además, la función pública implica ejercicio de poder y, como el poder es peligroso y corrompe, resulta lógico entender que todas las personas que manejan una cuota de poder y autoridad deban estar sometidas a un escrutinio mayor de sus actividades, debiendo, consecuencialmente, aceptar que tienen un ámbito más reducido de privacidad.

El CPT ha acertado en sus apreciaciones y ha interpretado la causal de reserva o secreto contenida en el artículo $21 \mathrm{~N}^{\mathrm{o}} 2$ de manera armónica con los principios constitucionales y con el espíritu de la Ley de Acceso a la Información Pública, sin perjuicio de la evidente coherencia con las normas que informan el derecho internacional de los derechos humanos.

En este orden de cosas, la Corte Interamericana de Derechos Humanos ha señalado que "el control democrático, por parte de la sociedad a través de la

Análisis de su reconocimiento, naturaleza jurídica y de las circunstancias que determinan que un interés sea público. Valencia: Tiranto lo Blanch. 
Jorge Luis Astudillo Muñoz

opinión pública, fomenta la transparencia de las actividades estatales y promueve la responsabilidad de los funcionarios sobre su gestión pública, razón por la cual debe existir un margen reducido a cualquier restricción del debate político o el debate sobre cuestiones de interés público" (Caso Palmara v. Chile, 2015, párrafo 83), por lo que derechos como el honor de los funcionarios públicos son merecedores de protección, pero "de manera acorde con los principios del pluralismo democrático" (Caso Ricardo Canese v. Paraguay, 2004, párrafo 127; Caso Herrera Ulloa v. Costa Rica, 2004, párrafo 127).

En otras palabras, la Corte Interamericana de Derechos Humanos, a propósito del derecho al honor frente al ejercicio de la libertad de expresión, en una interpretación que resulta del todo aplicable al derecho a la vida privada, por cierto, entiende que a los funcionarios del Estado se les debe aplicar un umbral diferente de protección, considerando el interés público que sus funciones y actividades reportan. "De esta forma, será la actividad la (que) determinará el escrutinio, razón por la cual incluso personas del ámbito privado que desarrollen actividades de interés público deberán estar sujetas a este mayor escrutinio", recalca Nash, siguiendo la doctrina de la Corte Interamericana de Derechos Humanos (Nash, 2008, p.1639).

Ahondando en estas reflexiones, el CPT ha sido enfático en indicar que "la función pública debe ejercerse favoreciendo el interés general sobre los intereses particulares, constituyendo la obligación elevada a rango constitucional que hemos citado, de declarar sus intereses y patrimonios en forma pública, un mecanismo para prevenir, por una parte, conflictos de intereses y, por otra, transparentar la evolución patrimonial de los directivos públicos, en el contexto de permitir un ejercicio de la función pública más transparente, con un mayor control ciudadano" (СРT C444-10).

Para la jurisprudencia del CPT, "la órbita de privacidad de los funcionarios que trabajan para la Administración del Estado es más reducida que la del resto de las personas" (CPT C377-13). Sobre este punto, el CPT insiste que "a mayor abundamiento, cabe recordar que la función pública, según lo establecido en los artículos $8^{\circ}$ de la Constitución Política de la República y $3^{\circ}$ de la Ley de Transparencia, debe ejercerse con probidad y transparencia, favoreciendo el interés general por sobre los intereses particulares, lo que conlleva el 
cumplimiento de una obligación, elevada a rango constitucional, de transparentar las actuaciones de los funcionarios de los órganos de la Administración del Estado ante la ciudadanía, por el solo hecho de ser funcionarios públicos al servicio de la misma" (СPT C377-13).

Siguiendo igual dirección, el CPT ha entendido que la entrega de registros de asistencia al trabajo de funcionarios de la Administración no constituye una afectación a sus derechos, especialmente a su derecho a la vida privada. Así, el CPT ha sido categórico en señalar que de ninguna manera se estima que los funcionarios públicos no tengan derecho a la protección de su vida privada, sino que "solo se sostiene que los funcionarios públicos, a diferencia de los empleados o profesionales del sector privado, tienen una vida privada mucho más restringida al realizar una función pública que deben ejercer con probidad y transparencia" (СРT C434-09).

En la misma línea también se ha resuelto que las calificaciones obtenidas por los funcionarios de la Administración son públicas y no quedan amparadas bajo la reserva o secreto "en virtud del interés público que revisten como mecanismo de rendición de cuentas, no solo ante las jefaturas, sino también ante la sociedad" (CPT A10-09). ${ }^{10}$ En consecuencia, el CPT entiende que "resulta relevante, para poder ejercer el control social, acceder a información sobre las calificaciones y notas de los funcionarios públicos" (СРT C3046-17).

Del mismo modo, el borrado del puntaje y nota de las calificaciones obtenidas por los mismos funcionarios no se encuentra justificado a la luz del mandado constitucional y legal, en consecuencia, el CPT ha ordenado "la entrega de instrumentos de medición de desempeño, registros de asistencia, currículum vitae, liquidaciones, hojas de vida y otros similares", tal como lo hemos señalado anteriormente (СРT C2364-17). ${ }^{11}$ En el mismo sentido, el CPT ha dicho que "resulta relevante, para poder ejercer el control social, acceder a la información sobre cursos efectuados a funcionarios públicos, con recursos públicos y dentro de su jornada laboral" (CPT C2364-17).

\footnotetext{
${ }^{10}$ En la misma línea: Decisión de Amparo A126-09, Miguel Rojas Zúniga con Fondo Nacional de Salud, 31/07/2009.

${ }^{11}$ En la misma dirección: Decisión de Amparo N ${ }^{\circ}$ C2365-17, C2447-17, Juan Pablo Gómez Concha con Carabineros de Chile, 26/09/2017.
} 
Jorge Luis Astudillo Muñoz

Por el contrario, "la fotografía del funcionario como su fecha de nacimiento no tienen vinculación con el ejercicio de la función pública y no son necesarios para la realización del control social" (СPT C2647-14) sobre los actos de la Administración, por lo que se puede concluir que su publicidad resulta irrelevante. De la misma manera, "la negativa a entregar datos personales de funcionarios de Carabineros de Chile como fecha y lugar de nacimiento, estatura, peso, estado civil, religión, nombre y profesión de cónyuge y motivo de la licencia médica, en cuanto a la patología diagnosticada, es una decisión que se ajusta a lo dispuesto en el artículo $21 \mathrm{~N}^{\circ} 2$ de la Ley de Transparencia en relación con la Ley $\mathrm{N}^{\mathrm{o}} 19.628$, al no mediar el consentimiento expreso de los titulares de dicha información" (CРT C3046-17).

También vinculado al ámbito de privacidad de los funcionarios públicos son los casos que ha debido resolver el CPT respecto de los currículums vítae que obran en poder de la Administración del Estado en varias de sus decisiones. Así, en términos generales, el CPT ha resuelto la entrega de estos, considerando el interés público comprometido, la imparcialidad de los procesos de licitación y de otros concursos y su control por parte de la ciudadanía (CPT A204-09). El СРТ ha sostenido que "si bien el currículum vítae contiene datos tales como el domicilio, RUT, trayectoria profesional y académica, datos de contacto, entre otros, los cuales constituyen datos personales, atendida la definición de estos en el artículo $2^{\circ}$, letra $\mathrm{f}$ de la Ley $\mathrm{N}^{\mathrm{o}} 19.628$, sobre protección de la vida privada, y conforme a su artículo $4^{\circ}$ en relación a su artículo $20^{\circ}$, dichos datos solo pueden ser tratados o comunicados por los órganos de la Administración del Estado, fuera de sus competencias, previo consentimiento de su titular, tratándose del currículum vítae de aquel personal empleado en los órganos y servicios públicos creados para el cumplimiento de la función administrativa, solo el acceso a dicha información permite a la ciudadanía evaluar las capacidades de la persona seleccionada para desempeñar su labor, resguardando el adecuado ejercicio de las funciones públicas" (СPT C95-10).

El CPT ha sentado lo que a nuestro juicio es la doctrina adecuada, pues ha distinguido entre los datos que son necesarios para evaluar el desempeño profesional del funcionario público y aquellos que no cumplen este objetivo. Los primeros deben ser divulgados, mientras que los segundos pueden quedar sometidos a la 
reserva legal. Así, en la decisión pronunciada en el Rol C95-10, el CPT sostiene que son datos necesarios para evaluar las capacidades para el desempeño de las labores encomendadas, por ejemplo, la trayectoria académica, profesional, laboral y aquellos que acrediten su capacidad, habilidades o pericia para ocupar el cargo público. Por el contrario, no tienen por objeto evaluar las antedichas capacidades, sino que aparecen incorporados en los currículums vítae como datos de contexto de estos, por ejemplo, el número de cédula nacional de identidad, el domicilio particular o profesional, la fecha de nacimiento, nacionalidad, estado civil, el número de teléfono o la dirección electrónica personal, etc.

En consecuencia, en virtud del principio de la divisibilidad, se ha entendido que se puede entregar el currículum vítae, tachando todos aquellos datos que no tienen por objeto evaluar las capacidades para el desempeño del cargo.

También en el marco del derecho a la vida privada, al СРT le ha correspondido pronunciarse sobre la publicidad de los informes y perfiles psicolaborales realizados dentro del contexto de concursos públicos.

Dentro de estos procesos, un ciudadano que no resulta seleccionado para un cargo en el Servicio de Impuestos Internos solicita al órgano administrativo: i) copia del informe y evaluación psicológica que se le practicó con ocasión del concurso; ii) copia del informe y evaluación psicológica de las personas que fueron seleccionadas para desempeñar la función y iii) el perfil ideal para entrar al servicio (СPT A110-09). Para resolver esta cuestión, el CPT consideró oportuno distinguir entre: i) los candidatos que han llegado a la etapa final del concurso, ii) el postulante mismo que requiere sus propios antecedentes y iii) los antecedentes de las personas designadas para el cargo (СРT A29-09). ${ }^{12}$

Así, frente a los antecedentes e informes psicolaborales del propio postulante, el CPT ha dicho que esta persona tiene derecho a conocer su evaluación personal realizada en el concurso respectivo, con la sola salvedad de las referencias que terceros hayan hecho de su persona, pues, si estas referencias fueran públicas, la sinceridad de estos testimonios se reduciría y les quitaría buena parte de su valor, de manera que, en este caso, el daño que originaría su difusión superaría las ventajas de publicarlas.

${ }^{12}$ En la misma línea: Decisión de Amparo No A35-09, Juan Velásquez Morales con Dirección Nacional del Servicio Civil, 11/08/2009. 
Respecto de los antecedentes de las personas seleccionadas para el cargo, el CPT ha entendido que la publicación de estos debe evaluarse considerando que tales informes han sido un antecedente fundamental para que dichos candidatos integraran la nómina para el cargo al que estos postularon y luego fueron seleccionados. En definitiva, se sostiene que la designación transforma a los candidatos en funcionarios públicos, por lo que deben quedar sujetos al escrutinio público y, por tanto, tolerar que su privacidad ceda ante el necesario control social. En las decisiones de amparo No A29-09 y No A110-09 se indica que "el interés público justifica que se conozcan los antecedentes que acreditan el cumplimiento de los requisitos y perfiles necesarios para haber sido designada en dicho cargo".

En todo caso, el CPT reconoce al respecto una importante salvedad: los datos sensibles de la persona seleccionada a la luz de la Ley $\mathrm{N}^{\circ} 19.628$, sobre protección a la vida privada. ${ }^{13} \mathrm{El}$ razonamiento que postula el CPT es el siguiente: de acuerdo con el artículo 2 letra g de la Ley $\mathrm{N}^{\circ} 19.628$, son sensibles todos aquellos datos personales que «se refieren a las características físicas o morales de las personas, tales como los hábitos personales, el origen racial, las ideologías y opiniones políticas, las creencias y convicciones religiosas, los estados de salud físicos o psíquicos y la vida sexual». Por su parte, el artículo 10 de la misma ley prescribe que no pueden ser "objeto de tratamiento los datos sensibles, salvo cuando la ley lo autorice, exista consentimiento del titular o sean datos necesarios para la determinación u otorgamiento de beneficios de salud que correspondan a sus titulares". Por tanto, si llegan a existir este tipo de datos, y en virtud del principio de la divisibilidad, ellos deberán ser tarjados antes de entregar al requirente la información solicitada.

Con ocasión del tratamiento que se debe dar a los antecedentes psicolaborales de las personas que han participado en el concurso público y que no han sido seleccionadas para el cargo, el CPT entiende que el ámbito de privacidad de estas personas se encuentra más protegido que respecto de un postulante que ya ha sido designado como funcionario público, básicamente porque su divulgación en nada contribuye a transparentar la función pública.

${ }^{13}$ Publicada en el Diario Oficial de 28/08/1999. 
El derecho a la vida privada de los funcionarios públicos frente al derecho de acceso a la información pública

En definitiva, en la decisión adoptada en el marco del amparo N ${ }^{\circ}$ A110-09, el CPT ordenó al órgano requerido, el Servicio de Impuestos Internos, entregar al requirente, postulante a un concurso público, su informe psicológico, el informe y la evaluación psicológica de las personas seleccionadas, con exclusión de los datos sensibles, además de la entrega del perfil específico para optar a dicho cargo.

Ante esta decisión de acoger parcialmente el requerimiento, el director del Servicio de Impuestos Internos interpuso un reclamo de legalidad ante la Corte de Apelaciones de Santiago. El órgano judicial resolvió, en relación con la primera de las hipótesis precedentemente planteadas, es decir, respecto de la entrega de los antecedentes psicolaborales del requirente, que del análisis de las disposiciones constitucionales y legales tomadas en cuenta "no se divisa razón valedera para que el reclamante no entregue al peticionario el informe psicolaboral que le fuera realizado con motivo de su postulación al cargo (...) ya que dicho informe fue realizado precisamente en base a los datos de carácter personal e incluso sensibles, que el peticionario debió proporcionar al servicio reclamante para el análisis de un especialista evaluador al tiempo de su postulación, consintiendo de paso que ellos, con otros antecedentes propios de su personalidad, formaran parte de la evaluación final, con las ponderaciones correspondientes, en los distintos aspectos comprendidos en el examen" (Corte de Apelaciones de Santiago, Rol 80-67).

A propósito de la solicitud de acceso a los antecedentes que conforman la acusación de acoso laboral por parte del denunciado, cuya culpabilidad no logró ser probada, el CPT estimó que la divulgación de dicha información afectaría no solo la vida privada de la referida funcionaria (denunciante), atendida la naturaleza de documentos que pudieron formar parte de su denuncia, como cartas, e-mail, grabaciones, fotografías, informes psiquiátricos o psicológicos, sino que también tendría el efecto de inhibir la formulación de denuncias por parte de potenciales víctimas de acoso laboral, sexual u otro tipo de conducta impropia al interior de organismos públicos, afectando con ello la labor investigativa y preventiva que el organismo reclamado puede desplegar ante futuras situaciones que impliquen algún tipo de responsabilidad funcionaria, afectando con ello el debido cumplimiento de las funciones del órgano (en este caso, el Servicio Agrícola y Ganadero) (СРT C429-14). ${ }^{14}$

${ }^{14}$ En la misma línea: Decisión de Amparo No C2049-15, N.N. con Ejército de Chile, 01/12/2015; Decisión de Amparo N ${ }^{\circ}$ C1834-17, Manuel García Andrade con Municipalidad de Santa Bárbara, 28/07/2017. 
Jorge Luis Astudillo Muñoz

Asimismo, el CPT también ha entendido que, "dada la especial naturaleza de la materia a que se refiere el sumario administrativo en comento, cabe tener presente que las declaraciones prestadas por los funcionarios en el curso de la investigación constituyen un insumo inestimable para una adecuada decisión por parte de la autoridad dotada de la potestad disciplinaria en el respectivo sumario administrativo. De este modo, existe un riesgo de que la divulgación de lo requerido inhiba a otros testigos a entregar ciertas opiniones o juicios personales, que solo se emiten bajo una razonable y evidente expectativa de reserva, lo que, en definitiva, afectaría futuras investigaciones y, por tanto, el adecuado cumplimiento de las funciones del órgano" (СРT C2795-17). ${ }^{15}$

A pesar de lo anterior, el CPT, en aplicación del principio de divisibilidad, considera que sí se debe dar acceso a los antecedentes necesarios para el control social del ejercicio de las funciones públicas en virtud del cual, una vez adoptada una decisión por parte de la autoridad dotada de potestad disciplinaria en el respectivo sumario administrativo, la ciudadanía conozca los fundamentos que han permitido arribar a determinadas conclusiones en dicho procedimiento disciplinario, sea cual fuere su resultado y la naturaleza de los hechos que hayan motivado su instrucción (СРT C2795-17).

De esta manera, el CPT concluye que, al margen de los fundamentos que han servido de base a la decisión final y la naturaleza de los hechos que han motivado la instrucción del procedimiento, son reservados los siguientes antecedentes (CPT C2795-17):

I- El cuaderno reservado del expediente solicitado, por cuanto contiene testimonios voluntarios prestados por particulares que no tienen el carácter de funcionarios públicos que concurrieron a declarar a dicha investigación, por lo que resulta procedente la reserva del mencionado cuaderno conforme a la Ley $\mathrm{N}^{\mathrm{o}} 19.628$.

II.- Respecto a las demás piezas del expediente, el órgano reclamado deberá tarjar la identidad de los particulares que declararon en el mismo, así como la

\footnotetext{
${ }^{15}$ En la misma línea: Decisión de Amparo No C2371-15, Daniela Arancibia Barros con Servicio Nacional de Geología y Minería (SERnageomin), 12/01/2016; Decisión de Amparo N $^{\circ}$ C1013-13 Luis Omar Risco Arriagada con Subsecretaría de Transportes, 30/04/2014.
} 
El derecho a la vida privada de los funcionarios públicos frente al derecho de acceso a la información pública

de los funcionarios públicos que concurrieron a declarar en calidad de testigos en el proceso y también de la parte denunciante. Al efecto, y con el objeto de que dicha reserva tenga efecto, la reclamada deberá, además, reservar cualquier dato o antecedente que permita inferir la identidad de los sujetos señalados precedentemente.

III.- En relación con los correos electrónicos, impresiones de conversaciones vía Whatsapp y relatos referidos a llamadas telefónicas, se ha estimado que constituyen información que se encuentra protegida por los derechos constitucionales consagrados en el artículo $19 \mathrm{~N}^{\mathrm{o}} 4$ y 5 de la Constitución Política.

IV.- El órgano reclamado, igualmente, deberá reservar las licencias médicas, así como también cualquier mención a patologías o estado de salud físicos o psíquicos del expediente respectivo, por constituir datos sensibles protegidos por la Ley $\mathrm{N}^{\mathrm{o}} 19.628$.

V.- Finalmente, se deberán tarjar los datos personales de contexto contenidos en el expediente, como domicilio, número de teléfono, correos electrónicos particulares, RUT, estado civil, fecha de nacimiento, etc., de conformidad a la misma Ley $\mathrm{N}^{\circ} 19.628$.

En consecuencia, desde su instalación en el año 2009 a la fecha, el CPT "ha razonado que atendido el tipo de función que desempeñan los servidores públicos, éstos están sujetos a un nivel de escrutinio de una entidad mayor, que supone un control social más intenso respecto de sus antecedentes profesionales. Luego, y en base a la referida premisa ha ordenado la entrega de instrumentos de medición de desempeño, registros de asistencia, currículum vítae, liquidaciones y otros similares, de funcionarios y ex-funcionarios. Sobre este punto y a mayor abundamiento, cabe recordar que la función pública, según lo establecido en los artículos $8^{\circ}$ de la Constitución Política de la Republica y $3^{\circ}$ de la Ley de Transparencia, debe ejercerse con probidad y transparencia, favoreciendo el interés general por sobre los intereses particulares, lo que conlleva el cumplimiento de una obligación, elevada a rango constitucional, de transparentar las actuaciones de los funcionarios y ex funcionarios de los órganos de la Administración del 
Jorge Luis Astudillo Muñoz

Estado ante la ciudadanía, por el solo hecho de ser, o haber sido, empleados públicos al servicio de la misma" (СРT C6237-18).

\section{Conclusiones}

La transparencia es un principio clave para el ejercicio del poder en el Estado democrático. La transparencia genera visibilidad y ésta permite combatir la corrupción. A pesar de la importancia del valor transparencia, el adecuado desarrollo de una sociedad democrática exige mantener una órbita excepcional de reserva o secreto. Las causales de reserva o secreto que autorizan a los órganos del Estado a negar la entrega de la información solicitada por la ciudadanía deben ser establecidas por ley y en forma taxativa, no permitiendo a su respecto una aplicación por analogía. Dentro de las causales de reserva o secreto que se suelen reconocer por los diversos ordenamientos jurídicos, cobran una particular importancia los derechos de las personas. En el caso chileno, la Ley $\mathrm{N}^{\mathrm{o}} 20.285$ establece en su artículo 21 estas causales, siendo una de ellas los derechos de las personas.

Por su parte, el derecho a la vida privada y el derecho a su protección resultan esenciales para el pleno desarrollo de la personalidad de las personas. Cada persona tiene un ámbito de su vida que desea mantener al margen del conocimiento de terceros. Las personas que ejercen funciones públicas también son titulares del derecho a la vida privada, sin embargo, atendida la naturaleza de sus cargos, especialmente en relación con el ejercicio de cuotas de poder, se ha entendido que el ámbito de privacidad es menor que el resto de los ciudadanos.

El CPT en Chile, por medio de sus decisiones, ha ido asentando esta idea en forma clara y contundente. El ejercicio de la función pública genera costos y uno de ellos es que la intromisión que los funcionarios del Estado deben tolerar a su privacidad es mucho mayor que el que sea exigible a cualquier particular.

El ejercicio del poder debe ser objeto de control y la teoría y la filosofía política están de acuerdo en que el poder debe ser controlado, pues de lo contrario puede lesionar la dignidad de las personas. En este orden de cosas, se entiende 
y justifica que la vida privada de las personas que prestan servicios dentro del Estado esté sometida a un escrutinio más alto. Con esto no se quiere afirmar que no sean titulares de una órbita importante de privacidad, sino que esta en muchos casos debe ceder ante otros bienes, como el control del poder, la transparencia, la probidad y el combate a la corrupción, en general el interés público.

\section{Bibliografía}

\section{Doctrina}

Bobbio, N. (1986) El futuro de la democracia, México D.F.: Fondo de Cultura Económica.

Cobos Campos, A. (2013) "El contenido del derecho a la intimidad".

Cuestiones constitucionales: Revista Mexicana de Derecho Constitucional (29), julio-diciembre, pp. 45-81.

Covarrubias Cuevas, I. (2015) "La vida privada de los funcionarios

públicos frente a dos derechos: el acceso a la información pública y la libertad de expresión". Revista Ius et Praxis, 21 (1), pp. 217-270. Díez-Picazo, L.M. (2005). Sistema de Derechos Fundamentales. 2a ed. Madrid: Thomson-Civitas.

Maqueo Ramírez, M. I. y otros. (2017). "Protección de datos personales, privacidad y vida privada: la inquietante búsqueda de un equilibrio global necesario". Revista de Derecho, Vol. XXX (1), junio, pp. 7796.

Martínez de Pinsón, J. (1997). "Vida privada e intimidad: implicaciones y perversiones”. Anuario de Filosofia del Derecho, XIV, pp. 717-738. Organización de Naciones Unidas. Convención de Naciones Unidas contra la corrupción, Mérida, 2003.

Nash Rojas, C. (2008). "Las relaciones entre el derecho a la vida privada

y el derecho a la libertad de información en la jurisprudencia de la 
Corte Interamericana de Derechos Humanos". Revista de Estudios Constitucionales, 6, 1, pp. 155-169.

Suárez Crothers, C. (2000). El concepto de derecho a la vida privada en el dereho anglosajón y europeo. Revista de Derecho de la Universidad Austral de Chile, XI, pp. 103-119.

\section{Jurisprudencia}

Consejo para la Transparencia (Chile):

Decisión de Amparo № C6237-18, Javier Morales Valdés con Fuerza Aérea de Chile, 23/05/2019.

Decisión de Amparo C3046-17, Álvaro Bahamondes Pardo con Carabineros de Chile, 26/12/2018.

Decisión de Amparo No C1180-18, Carlos Reyes con Armada de Chile, 16 de agosto de 2018.

Decisión de Amparo No C2795-17, Andrew Chernin de la Fuente con Subsecretaría de Relaciones Exteriores, 15/05/2018.

Decisión de Amparo N $N^{\circ}$ C1834-17, Manuel García Andrade con Municipalidad de Santa Bárbara, 28/07/2017.

Decisión de Amparo N ${ }^{\circ}$ C2371-15, Daniela Arancibia Barros con Servicio

Nacional de Geología y Minería (SERnAGeomin), 12/01/2016.

Decisión de Amparo No C2049-15, N.N. con Ejército de Chile, 01/12/2015.

Decisión de Amparo N C2647-14, Diego Grez Cañete con Municipalidad de la Estrella, 07/08/2015.

Decisión de Amparo No C429-14, Hernaldo Saldivia Pérez con Servicio Agrícola y Ganadero (SAG), 07/05/2014.

Decisión de Amparo No C1013-13 Luis Omar Risco Arriagada con Subsecretaría de Transportes, 30/04/2014. 
El derecho a la vida privada de los funcionarios públicos frente al derecho de acceso a la información pública

Decisión de Amparo C377-13, Juan Gómez Concha con Politica de Investigaciones de Chile, 03/07/2013.

Decisión de Amparo C444-10, Irene Yolanda Cordero Mansilla con Universidad de los Lagos, 08/10/2010.

Decisión de Amparo $\mathrm{N}^{\mathrm{o}}$ C95-10, Deisy Mancilla Guzmán con Municipalidad de Talagante, 29/06/2010.

Decisión de Amparo No A204-09, Sociedad Neira y Asociados Ltda. con Secretaría Regional Ministerial de Bienes Nacionales de la Región del Bío Bío, 16/03/2010.

Decisión de Amparo № C501-09, Cristián Valenzuela Véliz con Servicio Nacional de Turismo, 26/02/2010.

Decisión de Amparo C434-09, Juan Pablo Figueroa Lasch con Servicio de Salud Metropolitano Sur, 27/11/2009.

Decisión de Amparo No A323-09, Aldo Raggio Alvarado con Dirección Regional del Trabajo de Valparaíso, 20/11/2009.

Decisión de Amparo A10-09, Miguel Rojas Zúñiga con Ministerio de Vivienda y Urbanismo, 31/10/2009.

Decisión de Amparo No C2364-17, Decisión de Amparo No C2365-17, C2447-17, Juan Pablo Gómez Concha con Carabineros de Chile, 26/09/2017.

Decisión de Amparo No A47-09, Unidad Vecinal $N^{\circ} 13$, de Santa María de Manquehue con Ilustre Municipalidad de Vitacura, 15/09/2009.

Decisión de Amparo No A110-09, Mauricio Riquelme Álvarez con Servicio de Impuestos Internos, 25/08/2009.

Decisión de Amparo N ${ }^{\text {o }}$ A29-09, Juan Sebastián Walker Cerda con Dirección Nacional de Servicio Civil, 11/08/2009.

Decisión de Amparo A126-09, Miguel Rojas Zúñiga con Fondo Nacional de Salud, 31/07/2009.

Decisión de Amparo No A47-09, Raúl Sotomayor Valenzuela con Municipalidad de Vitacura, 15/07/2009.

Corte Interamericana de Derechos Humanos:

Caso Artavia Murillo y otros contra Costa Rica, 28 de noviembre de 2012. 
Caso Rosendo Cantú y otra contra México, 31 de agosto de 2010

Caso Fernández Ortega contra México, 30 de agosto de 2010.

Caso Palmara contra Chile, 22 de noviembre de 2005.

Caso Canese contra Paraguay, 31 de agosto de 2004.

Caso Herrera Ulloa contra Costa Rica, 2 de julio de 2004.

Tribunal Constitucional chileno. Control de constitucionalidad respecto del proyecto de ley que crea la Unidad de Análisis Financiero y modifica el Código Penal en materia de lavado y blanqueo de activos, Rol 389-03, 28 de octubre de 2003.

Tribunal Constitucional español. Sentencia 231/1988, 2 de diciembre de 1988.

Tribunal Europeo de Derechos Humanos:

Caso Axel Springer A G contra Alemania, 39954/08, 7 de febrero de 2012.

Caso S. And Marper contra Reino Unido, 30562/04 - 30566/04, 4 de diciembre de 2008.

Caso Peck contra Reino Unido, 44647/97, 28 de enero de 2003.

Caso Niemietz con Alemania, 13710/88, 16 de diciembre de 1992.

\section{Legislación}

Constitución Política de la República (Chile)

Ley 20.285 sobre acceso a la información pública (Chile), Diario Oficial del 20 de agosto de 2008 .

Ley 19.628 sobre protección a la vida privada (Chile), Diario Oficial del 28 de agosto de 1999.

Como Citar el Artículo: Astudillo, J. (2020). El derecho a la vida privada de los funcionarios públicos frente al derecho de acceso a la información pública. Un estudio a la luz de la jurisprudencia del Consejo para la Transparencia en Chile. Derecho Global, Estudios sobre Derecho y Justicia, V. (15) pp. 89-112 https://DOI.org/ 10.32870/dgedj.v5i15.277 